\title{
Кремниевый металл-оксид-полупроводник транзистор с зависимым контактом к карману и двухслойным поликремниевым затвором
}

\author{
(C) Т.А. Шоболова ${ }^{1}$, А.С. Мокеев ${ }^{1}$, С.Д. Рудаков ${ }^{1}$, С.В. Оболенский ${ }^{1,2}$, Е.Л. Шоболов ${ }^{1}$ \\ ${ }^{1}$ Филиал ФГУП „РФЯЦ-ВНИИЭФ“ „НИИИС им. Ю.Е. Седакова“, \\ 603137 Нижний Новгород, Россия \\ ${ }^{2}$ Нижегородский государственный университет им. Н.И. Лобачевского, \\ 603022 Нижний Новгород, Россия \\ E-mail: shobolova.ta@mail.ru, obolensk@rf.unn.ru, shelv@inbox.ru
}

Поступила в Редакцию 12 апреля 2021 г.

В окончательной редакции 19 апреля 2021 г.

Принята к публикации 19 апреля 2021 г.

\begin{abstract}
Проведено сравнение характеристик двух вариантов конструктивно-технологического исполнения кремниевого МОП-КНИ транзистора с контактом к подложке, совмещенным с истоком, с одним и двумя слоями поликремниевого затвора. По результатам численного моделирования показано, что транзисторы с двухслойным поликремниевым затвором имеют повышенную надежность, быстродействие и стойкость к ионизирующему излучению. Предложена самосовмещенная технология изготовления транзистора с зависимым контактом к карману и с двухслойным поликремниевым затвором, позволяющая реализовать транзисторы с большим отношением ширины к длине затвора (до 100 и более). Описанные конструктивнотехнологические особенности изготовления транзистора дают возможность дополнительного управления каналом транзистора, улучшают его характеристики и расширяют область применения.
\end{abstract}

Ключевые слова: МОП-транзистор, КНИ, двухслойный поликремний, зависимый контакт к карману, „широкий“ транзистор.

DOI: $10.21883 /$ FTP.2021.10.51444.48

\section{1. Введение}

К интегральным схемам (ИС), входящим в состав аппаратуры специального назначения, работающей в условиях воздействия внешних факторов (механических, климатических, специальных), предъявляются особые требования, к наиболее значимым из которых можно отнести следующие: уровень стойкости к воздействию особенных факторов, миниатюризация, быстродействие, высокая надежность, малое энергопотребление, широкий диапазон рабочих температур и другие. Для достижения необходимых характеристик ИС применяют различные схемотехнические и конструктивно-технологические решения, одним из которых может быть увеличение ширины транзистора в направлении оси затвора до значений, в 100 раз превышающих расстояние истоксток. В основном в технологии изготовления микросхем с проектными нормами 0.35 мкм используют элементы c $W / L$ от 0.27 до 10 , где $W$ - ширина элемента ИC, $L-$ его длина. Данные ограничения элементов связаны с особенностями операций фотолитографии, принципом увеличения интеграции элементов ИС и учетом изменения модуля напряженности электрического поля в слабо легированном слое кремния.

В элементах ввода-вывода микросхемы используются мощные транзисторы в качестве усилителей тока. Мощные транзисторы характеризуются высоким значением тока, что достигается увеличением ширины транзистора.
Отношение ширины транзистора к его длине является важной характеристикой, численное значение которого определяет геометрическую характеристику транзистоpa - количество квадратов. Таким образом, в элементах ввода-вывода микросхемы используют транзисторы с $W / L$ от 10 до 100 (т.е. от 10 до 100 квадратов), такие транзисторы называются „широкими“.

Фирма Honeywell в 2002г. опубликовала патент 6960810 В2, где описывается технология изготовления транзистора с двухслойным поликремниевым затвором [1]. Первый слой поликремния используется в качестве маски для формирования „охранных колец“ транзистора и способствует увеличению толщины слоя оксида кремния между вторым поликремнием и карманом транзистора, тем самым уменьшая паразитную емкость затвор-карман.

Предложенная технология изготовления транзистора способствует уменьшению напряженности электрического поля в подзатворном диэлектрике и тем самым приводит к уменьшению его напряжения пробоя и увеличению надежности. Данный эффект наблюдается благодаря рассовмещению края первого поликремниевого слоя и края кремниевого транзисторного островка [1].

„Охранное кольцо“ транзистора представляет собой легированный слой кремния, с концентрацией примеси, превышающей концентрацию кармана транзистора и располагающейся по краю кремниевого островка, между щелевой изоляцией и самим транзистором. Основная 
функция „охраны“ - уменьшение влияния положительных зарядов в щелевой изоляции, образовавшихся при радиационном воздействии. Таким образом, использование „охранных колец“ приводит к увеличению радиационной стойкости элементов схемы.

В данном патенте контакт к карману осуществляется посредством легированной области кремния под „охранным кольцом“. Таким образом, контакт к слаболегированному карману осуществляется с двух сторон транзисторной структуры, что исключает возможность использования данной технологии при изготовлении „широких“ транзисторов.

В данной статье описан способ изготовления оригинального транзистора с двухслойным затвором и зависимым контактом к карману, который позволяет получать „широкие“ транзисторы.

\section{2. Общие положения}

Транзистор с совмещенным с истоком контактом к карману или зависимым контактом представляет собой транзистор, где контакт к карману топологически находится на области истока [2].

На рис. 1 представлены структуры метал-окисел-полупроводник (МОП) транзисторов с однослойным (классическим) и двухслойным поликремниевым затвором (неклассическим). Овалами выделены области, где паразитная емкость „карман-затвор“ меньше, чем в областях, выделенных кружком. Данные области являются областями транзистора с повышенными напряженностями электрического поля.

В процессе изготовления транзисторной структуры с двумя слоями поликремния первый слой поликремния изначально используется в качестве маски формирования „охранного кольца“ транзистора, тем самым уменьшая влияние положительных зарядов, образовавшихся при $\gamma$-облучении в оксиде кремния, который окружает со всех сторон транзисторную структуру в качестве траншейной изоляции.

МОП-транзистор с совмещенным с истоком контактом к карману с двухслойным поликремниевым затвором обладает лучшими характеристиками, чем аналогичный классический транзистор. Транзистор с двухслойным поликремниевым затвором является более надежным, скоростным и стойким к воздействию особенных факторов [1]. Повышенная надежность такого транзистора связана с уменьшением напряженности электрического поля в верхних углах кремниевого островка и в подзатворном диэлектрике. Высота поликремниевого затвора определяется технологией изготовления транзисторных структур.

Так как у транзистора с двухслойным поликремниевым затвором толщина окисла между поликремниевой шиной и контактом к карману $h_{\text {ох2 }}$ больше на толщину первого поликремния, чем у транзистора с однослойным

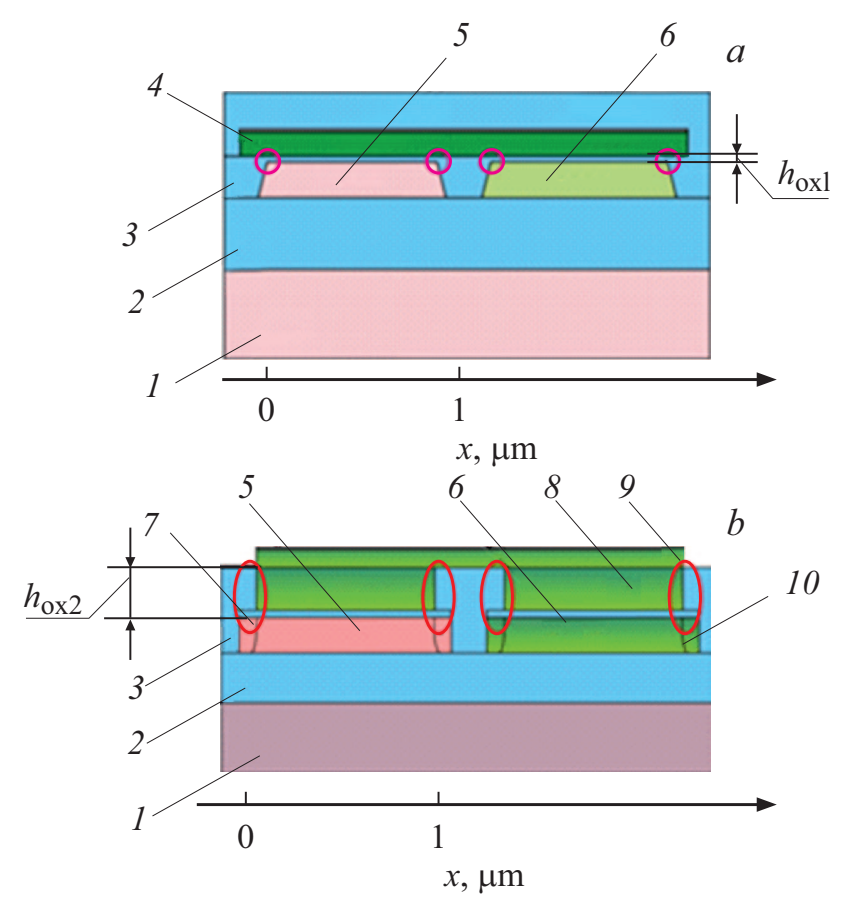

Рис. 1. Схематическое изображение поперечных сечений МОП-транзисторов с однослойным (a) и двухслойным $(b)$ поликремниевым затвором: 1 - кремниевая подложка; $2-$ слой захороненного оксида кремния; 3 - щелевая изоляция (оксид кремния); 4 - поликремниевая шина классического транзистора; $5-p$-карман $n$-МОП; $6-n$-карман $p$-МОП; $7-p^{+}$-охрана $n$-МОП; $8-$ первый слой поликремниевого затвора неклассического транзистора; $9-$ второй слой поликремниевого затвора или поликремниевая шина неклассического транзистора; $10-n^{+}$-охрана $p$-МОП. Овалами выделены проблемные области транзисторов. (Цветной вариант рисунка представлен в электронной версии статьи).

поликремниевым затвором $h_{\mathrm{ox}}$ (см. рис. 1 ), то, соответственно, паразитная емкость в первом случае меньше, чем во втором, так как отношение емкостей структур обратно пропорционально соотношению толщин окисла $h_{\text {ох2 }} / h_{\text {ох1 }} \approx 30$. Это сильно сказывается на скоростных характеристиках транзистора.

На рис. 2 приведены два варианта топологии транзисторов с совмещенным с истоком контактом к карману и с двухслойным поликремниевым затвором. Первый вариант (рис. 2, $a$ ) соответствует патенту [1], где контакты к карману расположены только на охранном кольце транзистора. Во втором варианте (предложенном нами, оригинальном, рис $2, b)$ топология включает контакты к карману не только на охранной области, но и в виде „Вставки““ в области истока.

\section{3. Физико-топологическая модель транзисторов}

В данной статье сравниваются транзисторы с двухслойным поликремниевым затвором, которые отличают- 


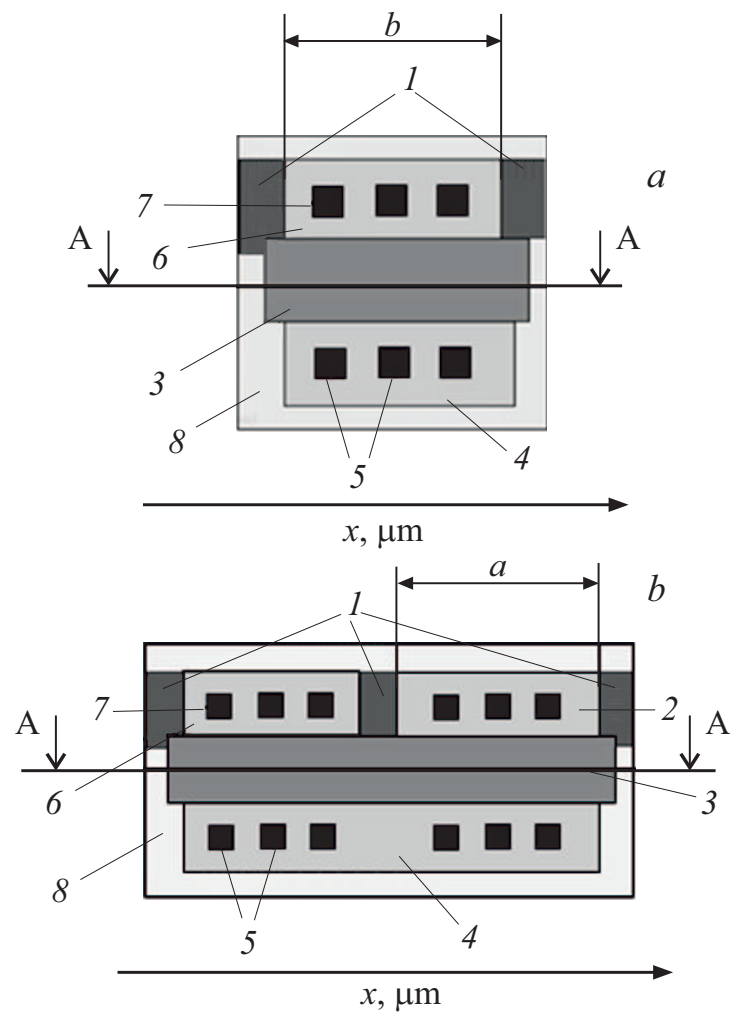

Рис. 2. Изображение топологии транзистора, предложенного в патенте [1] $(a)$ и широкого оригинального транзистора $(b)$ : 1 - контакт к карману; 2, 6 - кремниевый легированный слой (исток транзистора); 3 - поликремниевый затвор; 4 - кремниевый легированный слой (сток транзистора); 5 силицидированный контакт к стоку; 7 - силицидированный контакт к истоку; 8 - кольцевидная легированная область кремния - охранная область транзистора.

ся расстоянием между легированными областями кремния - контактами к подложке (см. рис. 2, $a$ и $b$ ), а именно $a=3.5, b=7$ мкм. Остальные геометрические характеристики были одинаковые.

Ширина оригинального и Honeywell транзисторов была выбрана 7 мкм. Такие транзисторы являются „широкими“, размером 20 квадратов (отношение ширины к длине транзистора).

B 3D модели оригинального транзистора шириной 7 мкм дополнительная вставка (контакт к карману) располагалась на расстоянии 3.55 мкм от края кремниевого островка.

Исследуемые транзисторы обладали следующими геометрическими характеристиками: длина поликремниевого затвора 0.35 мкм, длина LDD 0.1 мкм, истока/стока 0.1 мкм, ширина транзистора 7 мкм. Толщины слоев были выбраны согласно широко используемым в производстве микроэлектроники (МЭ) пластинам КНИ, где захороненный окисел и рабочий кремниевый слой составляют 0.2 мкм каждый, и выбранным проектным нормам.
Экспериментальные методы исследования являются не только дорогостоящими, времязатратными, но и порой недостаточными, возникает необходимость использования методов физико-математического моделирования с помощью ЭВМ [3].

В работе было проведено 3D моделирование МОП КНИ структур транзисторов с разными типами контактов к подложке, где концентрации легирования примесью одноименных кремниевых областей одного типа транзистора аналогичны другому. Необходимость проведения 3D моделирования объясняется тем, что 2D сечение транзистора является недостаточным для решения поставленной задачи - не может охватить необходимое для расчета влияние введения дополнительного контакта к карману на управляемость областью канала в транзисторе.

Математической основой TCAD является численное решение фундаментальной системы уравнений физики полупроводниковых приборов, которая для диффузионно-дрейфового механизма переноса носителей состоит из следующих уравнений:

$$
\begin{aligned}
& \mathbf{j}_{n}=\mu_{n} \cdot\left(n \nabla E_{c}+k T_{n} \nabla n-n k T_{n} \nabla \ln \gamma_{n}\right. \\
& \left.+\lambda_{n} f_{n}^{t d} k n \nabla T_{n}-1.5 n k T_{n} \nabla \ln m_{n}\right) ; \\
& \mathbf{j}_{p}=\mu_{p} \cdot\left(p \nabla E_{c}+k T_{p} \nabla p-p k T_{p} \nabla \ln \gamma_{p}\right. \\
& \left.+\lambda_{p} f_{p}^{t d} k p \nabla T_{p}-1.5 p k T_{p} \nabla \ln m_{p}\right) ; \\
& j_{n, \text { surf }}=-q n s_{n}, \quad j_{p, \text { surf }}=-q n s_{p} ; \\
& \nabla \cdot(\varepsilon \nabla \varphi+\mathbf{P})=-q\left(p-n+N_{D}-N_{A}\right)-\rho_{\text {trap }}, \\
& R_{\text {net }}^{S R H}=\frac{n p-n_{i, \text { eff }}^{2}}{\tau_{n}\left(n+n_{1}\right)+\tau_{p}\left(p+p_{1}\right)} ; \\
& n_{1}=n_{i, \text { eff }} \cdot \exp \left(\frac{E_{\text {trap }}}{k T}\right), \quad p=n_{i, \text { eff }} \cdot \exp \left(\frac{E_{\text {trap }}}{k T}\right) \text {; } \\
& R_{\mathrm{net}}^{A}=\left(C_{n} n+C_{p} p\right) \cdot\left(n p-n_{i, \mathrm{eff}}^{2}\right) \text {; } \\
& R_{\text {surt,net }}^{S R H}=\frac{n p-n_{i, \text { eff }}^{2}}{\frac{\left(n+n_{1}\right)}{s_{p}}+\frac{p+p_{1}}{s_{n}}} ; \\
& \nabla \cdot \mathbf{j}_{n}=q R_{\mathrm{net}, n}+q \frac{\partial n}{\partial t}, \quad-\nabla \cdot \mathbf{j}_{p}=q R_{\mathrm{net}, p}+q \frac{\partial p}{\partial t} ; \\
& \frac{\partial W_{n}}{\partial t}+\Delta \cdot \mathbf{S}_{n}=\mathbf{j}_{n} \cdot \frac{\nabla E_{c}}{q}+\frac{\partial W_{n}}{\partial t_{\text {coll }}} ; \\
& \frac{\partial W_{p}}{\partial t}+\Delta \cdot \mathbf{S}_{p}=\mathbf{j}_{p} \cdot \frac{\nabla E_{V}}{q}+\frac{\partial W_{p}}{\partial t_{\mathrm{coll}}}, \\
& \frac{\partial W_{L}}{\partial t}+\Delta \cdot \mathbf{S}_{L}=\frac{\partial W_{L}}{\partial t_{\text {coll }}},
\end{aligned}
$$

где $(1),(2)$ - уравнения плотности тока электронов и дырок; (3) - уравнение плотности поверхностного тока; (4) - уравнение Пуассона для распределения электростатического потенциала (4); (5) - уравнение темпа рекомбинации Шокли-Рида-Холла; (6) - уравнение концентрации равновесных носителей; (7) - уравнение 
темпа оже-рекомбинации; (8) - уравнение скорости поверхностной рекомбинации; (9) - уравнение непрерывности; (10),(11) - уравнения энергетического баланса для электронов, дырок и кристаллической решетки [4], где $j_{n}, j_{p}$ - плотность электронного и донорного токов, $\mu_{n} \mu_{p}$ - подвижность электронов и дырок, $n, p-$ концентрация электронов и дырок, $k-$ постоянная Больцмана, $E_{V}, E_{c}$ - уровень валентной зоны и зоны проводимости, $T_{n}, T_{p}$ - температура носителей заряда, $m_{n}, m_{p}$ - массы электронов и дырок, $j_{n \text {,surf }}$ - плотность поверхностного тока и т.д.

Так как геометрические размеры 3D структуры исследуемых транзисторов достигали 7 мкм, использовалась модель структурного проектирования Sentaurus Structure Editor (SDE). Этот модуль используется для графического проектирования 2D и 3D структур. Формирование структуры при этом включает в себя генерацию геометрической модели по областям структуры вместе с контактами, задание аппроксимирующих профилей легирования и определение процесса построения вычислительной конечно-элементарной сетки. При построении области структуры и границы раздела считались бездефектными. Ширина области пространственного заряда $p-n$-переходов зависит от заданной сетки и выбранных концентраций полупроводников.

При расчете характеристик использовались следующие начальные условия: напряжение на контактах равно нулю, температура электродов и структуры в целом равна $300 \mathrm{~K}$, контакты являлись омическими.

Для расчета приборно-технологической модели и при расчете электрофизических характеристик использовалась аддитивная сетка, измельчающаяся на границах раздела и в легированных областях материала. Размеры сетки изменялись от 0.1 до 0.001 мкм в кремнии. В подзатворном окисле сетка задавалась значительно меньше, согласно его толщине (0.0065 мкм).

\section{4. Результаты и обсуждения}

В таблице приведены следующие характеристики классического и оригинального транзистора с совмещенным с истоком контактом к карману: $C$ - паразитная емкость „затвор-карман“, $S-$ крутизна, $t-$ время задержки переключения, $U_{\mathrm{br}}$ - пробивное напряжение подзатворного диэлектрика транзистора.

Таким образом, из таблицы видно, что транзисторы с двухслойным поликремниевым затвором обладают лучшими характеристиками, чем классические.

Характеристики классического и оригинального транзисторов

\begin{tabular}{l|c|c|l|c}
\hline Тип транзистора & $C$, пФ & $S$ & $t, \mathrm{Hc}$ & $U_{\mathrm{br}}, \mathrm{B}$ \\
\hline Классический & 8.56 & $1.45 \cdot 10^{-5}$ & 0.213 & 12 \\
Неклассический & 0.28 & $2.6 \cdot 10^{-5}$ & 0.18 & 15
\end{tabular}

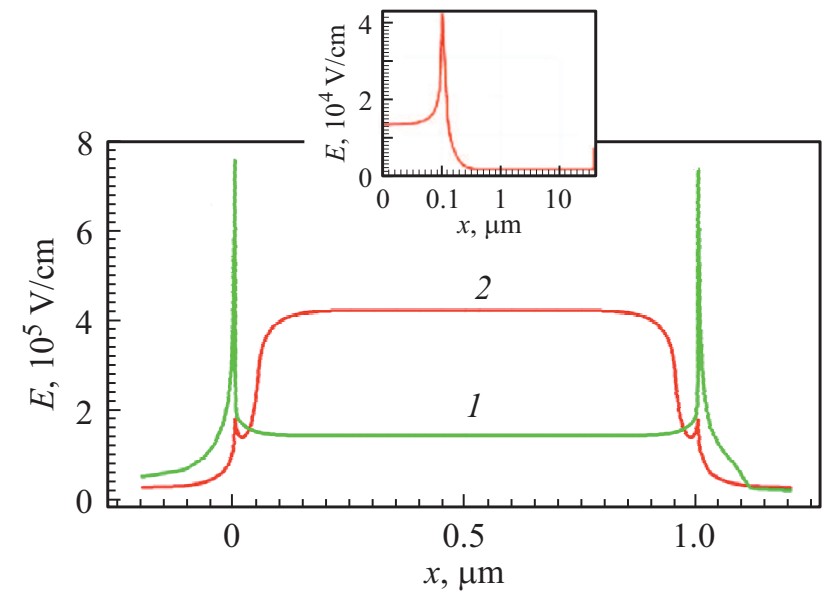

Рис. 3. Распределение напряженности электрического поля в подзатворном диэлектрике вблизи кремниевого островка для транзистора с однослойным поликремниевым затвором (1) и транзистора с двуслойным поликремниевым затвором (2). На вставке приведено распределение модуля напряженности электрического поля в слаболегированном $\left(N=10^{17} \mathrm{~cm}^{-3}\right)$ кремниевом полупроводниковом образце прямоугольной формы длиной $x$.

Для визуализации отличия распределения напряженности поля в транзисторах рассмотрим распределение напряженности поля в подзатворном диэлектрике, на расстоянии $4 \cdot 10^{-4}$ мкм от поверхности кремниевого островка при напряжении на поликремниевой шине $1 \mathrm{~B}$, а на кармане транзистора 0 (см. рис. 3). Кремниевый островок моделировался шириной 1 мкм и располагался при $0<x<1$.

Также при разработке технологии изготовления транзистора с зависимым контактом к карману необходимо учитывать зависимость напряженности электрического поля от расстояния до контакта. Особенно заметно это явление в низколегированных образцах, так как с уменьшением концентрации примеси полупроводника увеличивается его сопротивление [5].

Для анализа влияния расстояния между контактами к карману на управляемость области канала посредством приложения напряжения на контакт к карману было проведено моделирование 2D кремниевой полупроводниковой структуры, легированной аналогично карману (см. вставку на рис. 3).

Напряжение пробоя подзатворного диэлектрика классической структуры транзистора в 4 раза ниже напряжения пробоя подзатворного диэлектрика транзисторной структуры с двухслойным поликремниевым затвором. Таким образом, очевидно, что оригинальный транзистор является более надежным, чем классический транзистор.

Как указывалось ранее, в элементах ввода-вывода ИС используются „широкие“ транзисторы. Для проектирования „широких“ транзисторов необходимо учитывать эффект уменьшения напряженности электрического поля при удалении от контакта к карману [5]. Отрица- 


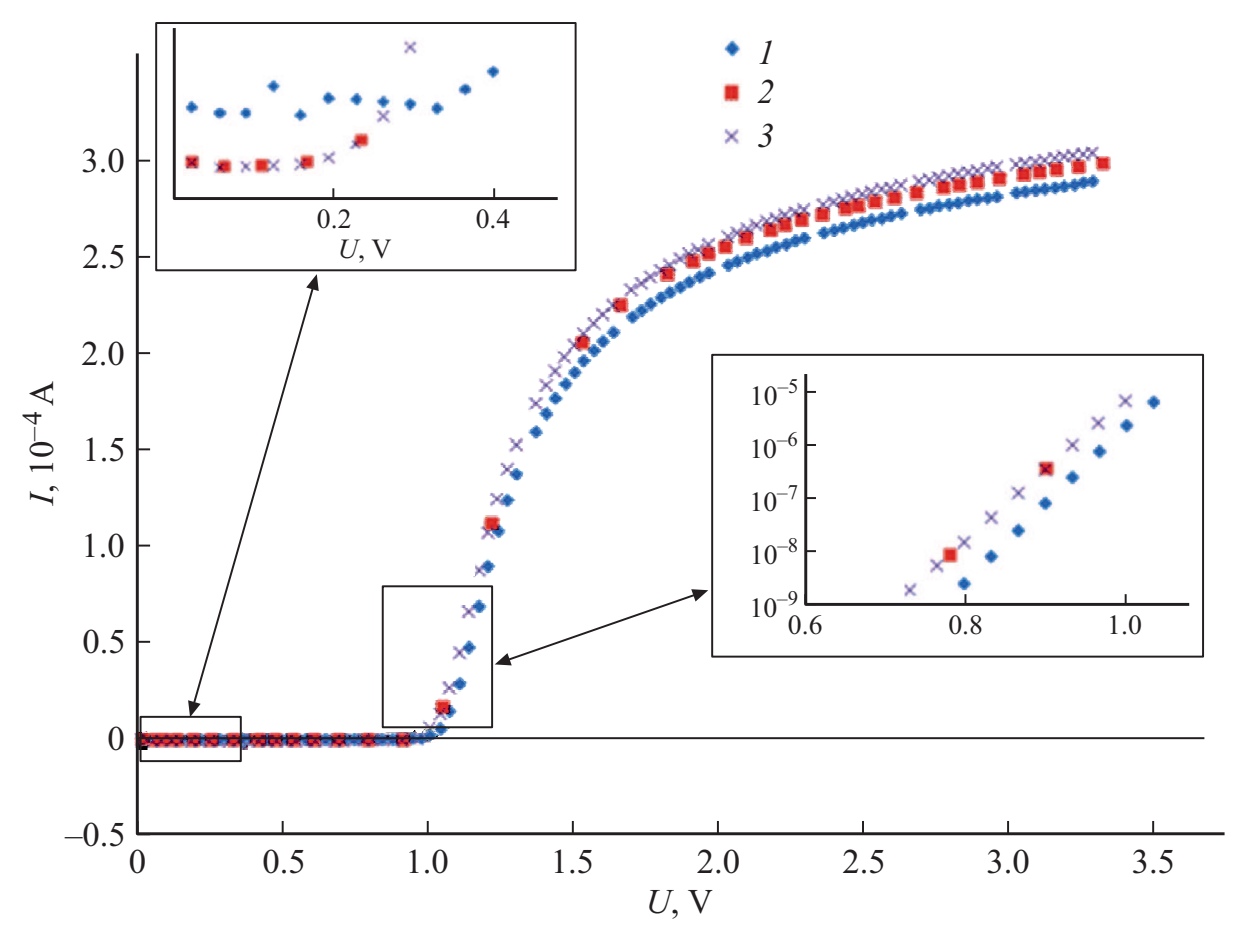

Рис. 4. Передаточные характеристики транзисторов оригинального и транзистора Ноneywell: 1 - оригинального транзистора с напряжением на подложке -0.5 B; 2 - транзистора Honeywell с напряжением на подложке -0.5 B; 3 - транзистора Honeywell c напряжением на подложке $0 \mathrm{~B}$.

тельным результатом данного эффекта является нарушение работы транзистора, а именно указанное может привести к задержке открытия канала. На вставке рис. 3 приведен результат моделирования в TCAD - pacпределение модуля напряженности электрического поля 2D структуры, где между двумя контактами (см. вставку на рис. 3) подавалось напряжение $V=0 \mathrm{~B}(x=35$ мкм) и напряжение $V=3.3 \mathrm{~B}$ ( $x=0.1$ мкм) соответственно. Исследуемая структура представляла собой кремниевый слой, толщиной 0.2 мкм, что соответствует толщине рабочего слоя структуры КНИ, и шириной 35 мкм, легированный фосфором концентрацией $10^{17} \mathrm{~cm}^{-3}$. Приведенное значение концентрации соответствует концентрации примеси в кармане транзистора. Контакты моделировались точечными на ширине 0.1 и 35 мкм.

Таким образом, при создании геометрии транзистора для улучшения управляемости областью канала, осуществляемой посредством подачи напряжения на контакт к карману, необходимо учитывать распределение напряженности электрического поля в легированном полупроводнике.

Учитывая выше перечисленные особенности, был разработан способ изготовления транзистора с зависимым контактом к карману и двухслойным поликремниевым затвором на структурах КНИ (оригинальный транзистор) шириной от 10 до 100 квадратов. Самосовмещенная технология такого транзистора отличается от той, что предложена в патенте Honeywell [1], введением дополнительного топологического слоя, который на гото- вой структуре состоит из высоколегированной области кремния „вставки“ (контакта к карману, см. рис. 2) и слаболегированной области кремния, посредством которой происходит соединение „вставки“ с карманом транзистора. Так как предложенный контакт к карману не привязан к „охранному кольцу“ транзистора, на области истока можно сформировать несколько подобных контактов к карману („вставок“), тем самым учесть и исключить нежелательное падение напряженности электрического поля в кармане и улучшить управляемость областью канала посредством подачи напряжения на контакт к карману.

Предложенное изменение контакта к транзистору не приводит к существенному изменению электрофизических параметров, но способствует расширению области использования транзистора.

Моделирование передаточной характеристики осуществлялось при двух режимах. Первый режим моделирования: на исток и контакт к карману напряжение не подавалось (0 В), на сток подавалось напряжение 0.1 В. Рассчитывался ток стока в диапазоне напряжений на затворе от 0 до $3.3 \mathrm{~B}$. Полученные передаточные характеристики транзисторов были абсолютно идентичны друг другу.

Второй режим моделирования включал следующие параметры: на исток напряжение не подавалось (0 B), на стоковый контакт подавалось напряжение $0.1 \mathrm{~B}$, на контакт к карману подавалось напряжение -0.5 В. Рассчитывался ток стока в диапазоне напряжений на затворе 
от 0 до 3.3 В. Полученные передаточные характеристики двух типов транзисторов различны. Начальный ток в оригинальном транзисторе превышает начальный ток в транзисторе Honeywell (см. pис. 4).

Более того, приложение напряжения на карман широкого транзистора Honeywell не привело к какому-либо изменению передаточной характеристики данного транзистора, что свидетельствует о том, что предложенный вариант формирования контакта к карману не подходит для широких транзисторов.

Приложение отрицательного напряжения на карман широкого оригинального транзистора привело не только к увеличению начального тока стока, но и к увеличению порогового напряжения транзистора (сдвигу характеристики вправо). Величины сдвига и увеличения начального тока зависят от значения приложенного напряжения. На рис. 4 при приложении небольшого напряжения, относительно напряжения питания, на контакт к карману оригинальной транзисторной структуры наблюдается динамика BAX. Для структуры Honeywell этого не наблюдается.

Полученные результаты свидетельствуют о лучшем управлении областью канала „широкого“ транзистора посредством контакта к карману в оригинальной структуре, чем в структуре Honeywell.

Таким образом, оригинальный транзистор не только обладает всеми преимуществами транзистора с двухслойным поликремниевым затвором, но и может использоваться в элементах ввода и вывода ИС.

\section{5. Заключение}

В ходе данной работы был рассмотрен транзистор на КНИ с двухслойным поликремниевым затвором. С помощью математического моделирования в САПР TCAD показано преимущество транзистора с двухслойным поликремниевым затвором над аналогичным транзистором с однослойным поликремниевым затвором. Такие транзисторы вследствие уменьшения напряженности электрического поля в верхних углах кремниевого островка и подзатворном диэлектрике являются более надежными. Вследствие использования охранной области транзистора - являются более стойкими к воздействию особенных факторов. Технология использования двухслойного поликремниевого затвора способствует уменьшению паразитной емкости „затвор-карман“ и, как следствие, увеличению быстродействия транзистора.

В статье также предложен способ изготовления „широкого“ транзистора КНИ с совмещенным с истоком контактом к подложке с двухслойным поликремниевым затвором. Данный транзистор не только обладает вышеперечисленными преимуществами над классическим транзистором, но и, вследствие модифицирования контакта к карману, позволяющему формировать более двух контактов к карману на области истока, имеет более широкую область использования. Предложенный способ формирования контактов к карману позволяет варьировать ширину транзистора от 10 квадратов до 100 включительно без ухудшения управляемости областью канала транзистора.

\section{Конфоликт интересов}

Авторы заявляют, что у них нет конфликта интересов.

\section{Список литературы}

[1] Патент US 6960810 B2, P. Fechner, Honeywell International Inc., Self-aligned body tie for a partially depleted SOI device structure, 2005.

[2] Патент US 6154091 A, H01L, J.P. Pennings, G.E. Smith, M.H. Wood, SOI sense amplifier with body contact structure, 1999.

[3] К.О. Петросянц, Д.А. Попов, Д.В. Быков. Электроника, 22, 569 (2017).

[4] Т.А. Шоболова, Ю.А. Кабальнов, С.В. Оболенский. Электрон. техн., сер. 2, Полупроводники, 3 (258), 34 (2020).

[5] С. Зи. Физика полупроводниковых приборов (М., Мир, 1984) т. 1.

Редактор А.Н. Смирнов

\section{Silicon metal-oxide-semiconductor transistor with dependent pocket contact and two-layer polysilicon gate}

\author{
T.A. Shobolova ${ }^{1}$, A.S. Mokeev' ${ }^{1}$, S.D. Rudakov', \\ S.V. Obolensky ${ }^{1,2}$, E.L. Shobolov ${ }^{1}$ \\ ${ }^{1}$ Branch of RFNC-VNIIEF \\ „NIIIS named after Yu.E. Sedakov", \\ 603137 Nizhny Novgorod, Russia \\ ${ }^{2}$ Lobachevsky State University of Nizhny Novgorod, \\ 603022 Nizhny Novgorod, Russia
}

\begin{abstract}
The author compares the characteristics of two constructive-technological versions of MOS SOI transistor with a wafer contact multiplexed with a source and with one and two layers of polysilicon gate. Following the results of the digital simulation, it is demonstrated that the transistors with two-layer polysilicon gate have an improved reliability, a better processing speed and resistance to the ionizing radiation. In the article, it is proposed to use a self-aligned technology of manufacturing transistors with dependent pocket contact and twolayer polysilicon gate that permits to implement transistors with a big proportions of width of the gate to the length (up to 100 times and more). The described constructive-technological features of transistor manufacturing provide an opportunity of an additional transistor channel control, improve its characteristics and expand its application area.
\end{abstract}

